\title{
Ecodesign - Design and Evaluation of an E-Learning System for Vocational Training
}

\author{
Margit Pohl ${ }^{1 *}$, Markus Rester ${ }^{1}$, Peter Judmaier ${ }^{2}$, Kerstin Stöckelmayr $^{1}$ \\ ${ }^{1}$ Institute of Design and Assessment of Technology, Vienna University of Technology \\ Favoritenstraße 9-11 / 187, A-1040 Vienna, Austria \\ *margit@igw.tuwien.ac.at \\ ${ }^{2}$ Institute of Engineering Design and Logistics Engineering, Vienna University of Technology \\ Getreidemarkt 9 / 307, A-1060 Vienna, Austria
}

\begin{abstract}
Summary: At the Vienna University of Technology an online course in sustainable product design has been developed. The aim of this course is to offer vocational training for professionals in product design. The interface of the e-learning system is easy to understand. The whole system is adapted to the needs of the target group. Communication and cooperation play an important role for the e-learning system. Extensive evaluation is supposed to ensure the effectivity of the system.
\end{abstract}

Keywords: collaborative learning, vocational training, life-long learning, evaluation of e-learning systems

\section{Introduction}

A common argument which can be found in the literature again and again is that lifelong learning and vocational training are becoming increasingly important (see e.g. [RS02], [JHG03]). An area for which this argument is definitely valid is ecology, especially because this topic still receives too little attention in traditional university curricula. At the Vienna University of Technology vocational training courses in this area have been offered for several years, especially in Ecological Product Design [WZ01]. These courses were held as normal lectures. One of the problems of these courses was that participants not coming from Vienna had difficulties to attend. Therefore, we developed the concept of an online course with a restricted amount of face-to-face teaching.

Distance Education is often seen to have special advantages for adult learning (see e.g. [JHG03]). Working adults and mothers of little children are frequently unable to attend vocational training courses held in the form of face-to-face lectures. Distance Education is a possibility to offer education to these people. Nevertheless, it is necessary to adapt these courses to the needs of adult learners. In this context, a problem-based approach and the consideration of the professional experience of the learners are important [RS02]. In addition, the motivation of adult learners in continuing education is usually higher than that of the younger university students [JHG03]. These considerations suggest the adoption of constructivist approaches for the design of e-learning systems. Furthermore, we think that it is important to support the empathy between teachers and learners and to assist the learners in a comprehensive manner to avoid the high drop-out ratio typical for Distance Education [Ho01].

In the following paper, we describe the concept of the Ecodesign e-learning course. To ensure the efficiency of this system we also conducted a comprehensive evaluation of the whole course. At every step in the development process specific evaluation methods were adopted. The results from the usability tests of the first prototype of the system are described elsewhere [PR04]. The work described in this paper rather analyzes whether the main ideas behind the Ecodesign e-learning system are adapted to the needs of the target group or not. An important point in this context was how to design electronic communication and cooperation for adult learners with little computer literacy (as is the case in our target group).

\section{Description of the System}

An important aspect of the didactic approach underlying the Ecodesign e-learning system is the usage of a metaphor. A metaphor can make learning easier by relating to well-known situations. It can also help to provide a meaningful context for the material presented in the system (see e.g. [PRS02], [Sc97]). 
We chose an office as a metaphor. The single tasks are located in individual rooms. The function of these rooms is somehow related to the task it represents. In this way we ensured the consistency of the metaphor (see e.g. [Sc97], [Ni00]). Based on the usability tests we chose the following rooms: an office (fig. 1, left), a library (fig. 1, right), and a room for communication. The office contains all the examples which the learners have to solve and essential information to solve these problems. This information is organized as dossiers. The library contains additional material and material like standards which serve as a reference. The room for communication contains a discussion forum, an access to a chat, and general and administrative information for all participants.
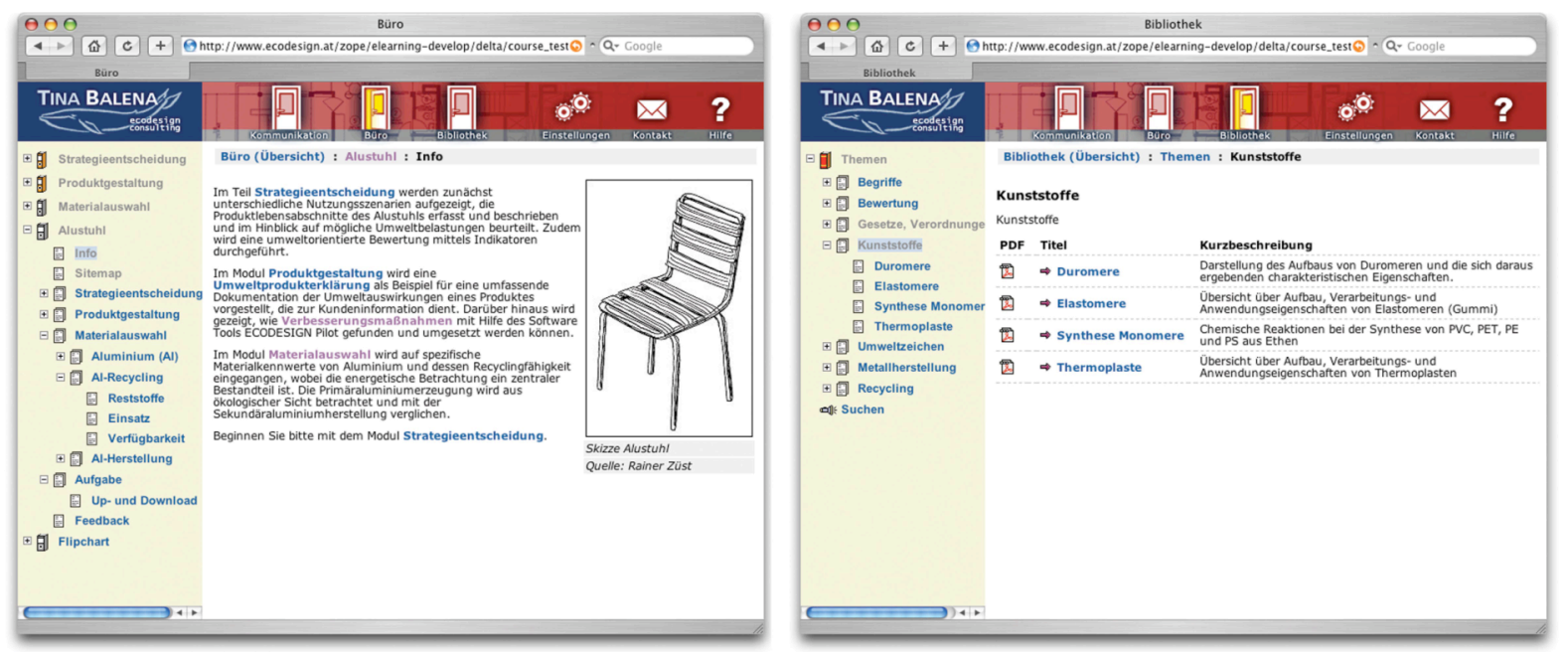

Figure 1: The ECODESIGN E-Learning System: Typical Node of a Dossier in the Office Room (Left) and Documents Ordered by Topics in the Library Room (Right)

In the library, all the documents are stored as PDF-files. The distinction between essential information (in the office) and additional information (in the library) enabled us to reduce the size of the dossiers in the office and to organize them in hypertextual manner.

The maximum number of participants in a course is 20 . The course is delivered in the form of Blended Learning. The face-to-face meetings are fairly cumbersome for the participants from outside Vienna. Nevertheless, they allow an intensity of interaction and learning which makes up for the trouble of traveling. The duration of the course is four months. There are three face-to-face meetings during the course, one at the beginning, one in the middle, and one in the end. The face-to-face meetings make up 30\% of the course. In between those face-to-face meetings are two online learning phases during which the participants are supported by an online tutor.

It is well-known that online learning is difficult for some people because of a lack of motivation. We decided to offer active learner support to the participants [RV03]. An online tutor helps all the participants with their problems, organizes communication and cooperation during the course, and motivates them to keep going. The online tutor is also present in the face-to-face meetings but the structuring of online learning is her main task. It was her function to provide a motivating learning situation and mutual understanding between trainers and learners (active tutoring). MacPherson and Nunes [MN04] also argue that tutors are vital for the success of elearning.

We decided to develop our own e-learning system because the existing platforms contain a huge amount of features which are not needed for our course. Such features are usually costly and distract from the main goal of the system. The interfaces of such platforms are usually complex and difficult to learn [Sc01]. In contrast to that, we wanted to develop a lean e-learning system which is simple and easy to understand. Therefore, we decided to use the Open-Source Web-Application-Server Zope (www.zope.org) as a basis for our e-learning system.

In October 2004 the Ecodesign course was institutionalized as a continuing education program at the Vienna University of Technology. The course lasts one semester, comprises 75 learning units and counts 5 ECTS points. The first course took place in the winter semester 2004/2005. There were eleven participants from various companies and backgrounds. The participants were obviously very motivated by the course. One indication for this is that several of the participants still meet regularly even after the course has ended to exchange their personal experiences with Ecodesign. In the winter semester of 2005/2006 another course currently takes place. 


\section{Methods of Investigation}

Lowyck [Lo02] points out that design decisions for e-learning systems are often founded in intuition rather than in systematic reasoning and based on empirical research. He suggests that such an approach has its limits because relevant insights have to be made again and again. . This is also argued by Dalsgaard [Da05]. One possibility to overcome such limits are guidelines (see e.g. [CM03]) based on scientific research. In the course of the project we developed a set of guiding principles for the Ecodesign e-learning systems. These guidelines are based on previous work [Po04]. These guidelines also formed the basis for the evaluation process. Important aspect for these guidelines were the organization of navigation; usage of pictures, animations, and videos; the design of communication processes and the question whether the contents of the course was relevant for the professional practice of the participants. We adopted a mixture of quantitative and qualitative research methods. On the one hand, we conducted interviews with the participants of the course, on the other hand we carried out a logfile analysis of the users' actions. Unluckily, more extensive testing with the real users was not possible because of the time constraints of the participants. Most of the participants worked full-time, and some of them did not live in Vienna, so they were very reluctant to spend more than one hour for tests of the Ecodesign elearning system. In the following, some of the results of the interviews and the logfile analysis are discussed.

\section{Results of the Interviews}

The interviews with the participants of the course took approximately one hour. They were structured according to the guidelines mentioned above. The interviews were tape recorded and transcribed.

Most participants found, that the Ecodesign e-learning course was useful for their work practice and adapted to their needs.

We tried to ensure that the structure and the navigational facilities of the system was as clear and simple as possible, so that the participants were able to concentrate on the contents of the system. To a certain extent, we could achieve this goal. All participants but one said that the system was simple and clear and the structure understandable. We offered several possibilities of navigation to the participants: a tree-like structure on the left of the screen (similar to the Windows Explorer), breadcrumbs (a description of the hierarchical path on top of the main text field), a sitemap and links within the text (see fig. 2).
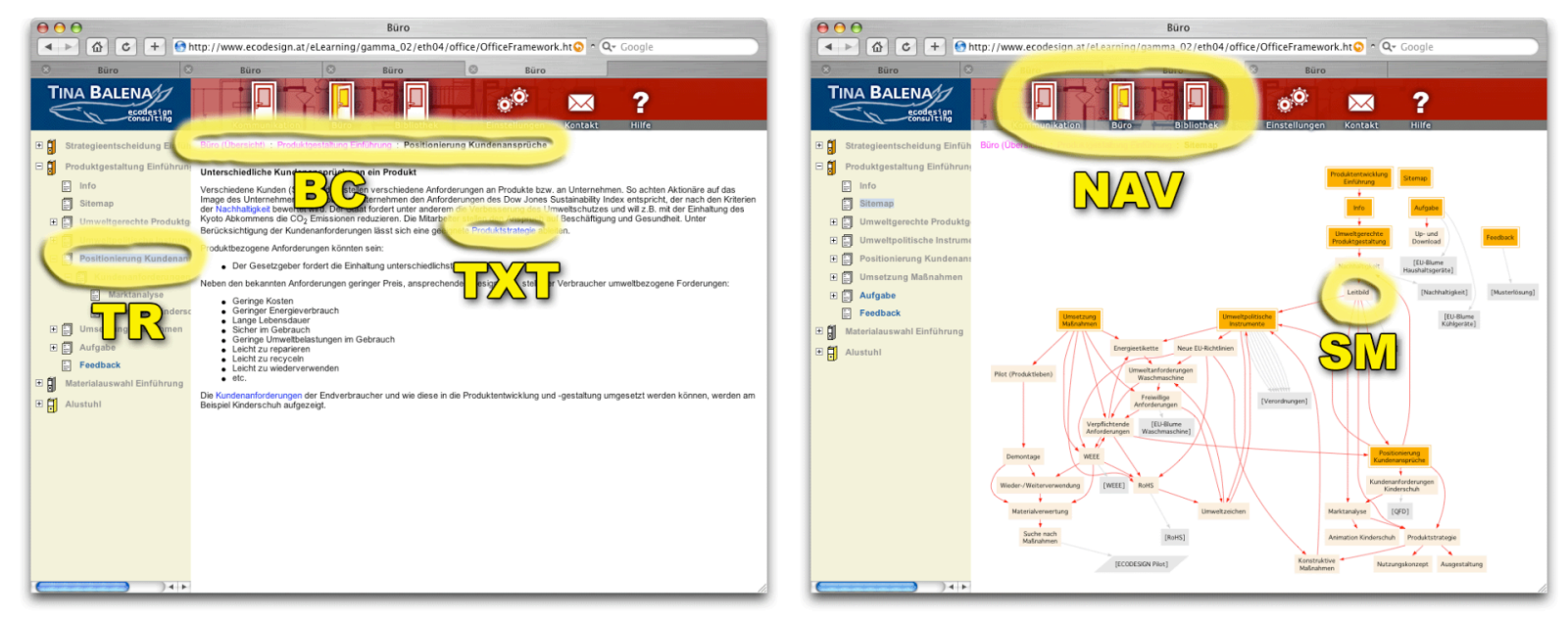

Figure 2: Introduced Categories of Navigational Practices: Tree, Breadcrumbs, Text-Links, Navigation Bar and Sitemap

Most participants of the course (9) found the tree structure the most comfortable navigation possibility to use. The attitude towards the sitemap was rather controversial. Some of the participants found this feature very positive (5) because it gave them an overview of the system. Others found that the sitemaps were chaotic and that they did not know what to do with it (6). Even those persons who had a positive attitude did not use the sitemap for navigation but rather to get an overview of the material. Breadcrumbs were only used by two persons. They only used them for orientation, not for navigation. The links in the text were only used by a few people. Non-hierarchical links which led to a different part of the document were criticized by several people as completely confusing. Others found that they gained interesting insights from these links. 
Communication among the participants and between participants and trainers was a very important feature of the system. Right from the beginning of the course, interaction between participants and trainers was organized by the online tutor. Chats regularly took place at appointed times. The participants also had the possibility to ask questions in the discussion forum. In principle, all participants of the course found communication as such a very valuable part of the learning process although there were divergent opinions as to which form of communication was best. The chat was criticized by many participants (7). It must be mentioned, that some participants had technical problems with the chat (especially because of restrictive firewalls in their companies). Apart from the technical problems, participants also stated that chats are chaotic, that you never know whether an answer belongs to your own question or to somebody else's, that time-lags are annoying and that chats become confusing when many people take part. In addition, participants complained that it is not possible to discuss problems in great detail in chats and to get comprehensive answers. Some of the participants also found it difficult to be prepared for every chat, that is to be able to ask intelligent questions. Sometimes, no discussion at all happened in the chat because nobody asked any questions despite the activity of the online tutor who tried to motivate the participants to take part in the discussion. Lawless and Allen [LA04] argue that problems with online collaboration might be due to stress. Learners feel pressured to support their team members. Other participants found the chat very interesting. They enjoyed getting a more personal contact to other learners and trainers. The discussion forum was appreciated by all the participants, even if some of them pointed out that the design of it could be improved. The support from the online tutor was praised by all the participants. Active tutoring was probably responsible for the fact that all participants finished the course successfully despite the high workload.

\section{Results of the Logfile-Analysis}

The Ecodesign e-learning course started in October 2004 and lasted until January 2005. During the whole time all activities of the participants in the e-learning system were recorded in the form of a Web-Server-Logfile. The eleven participants produced between 10303 and 32066 lines in the Zope logfile (Z2.log). All in all, we had to analyze 198016 lines (this is approximately $78.5 \mathrm{MB}$ ).

The navigational behavior of every of the eleven participants was analyzed. In addition to the five main forms of navigation (see fig. 2) we also took additional factors into consideration: number of clicks on links leading to postings in the discussion forum (VP view posting); number of clicks on links leading from the office to the library (O2L office to library); number of clicks on PDF files in the library (PDF). The last three categories might also be seen as text links but we think their function differs considerably from normal text links, therefore we analyzed them separately.

Table 1 contains a minimum and a maximum number for all categories. These numbers show the maximum (minimum) number of clicks in this category for a specific user, the average number of clicks in this category and the percentage across all users. The values in the min- and max-lines do not necessarily come from one single user.

\begin{tabular}{|c|cccrcrrrr}
\hline & SUM & NAV & \multicolumn{1}{c}{ TR } & BC & TXT & SM & VP & O2L & PDF \\
\hline Min & 956 & 84 & 437 & 0 & 72 & 1 & 63 & 12 & 37 \\
Max & 3352 & 289 & 2262 & 482 & 883 & 479 & 191 & 112 & 293 \\
Avg & 1711.6 & 180.8 & 897.7 & 47.0 & 303.5 & 47.8 & 102.0 & 33.6 & 99.2 \\
\% & $\mathbf{1 0 0 . 0}$ & $\mathbf{1 0 . 6}$ & $\mathbf{5 2 . 4}$ & $\mathbf{2 . 7}$ & $\mathbf{1 7 . 7}$ & $\mathbf{2 . 8}$ & $\mathbf{6 . 0}$ & $\mathbf{2 . 0}$ & $\mathbf{5 . 8}$ \\
\hline
\end{tabular}

Table 1: Usage of Various Navigational Practices by 11 Users. Navigation Bar (NAV), Tree (TR), Breadcrumbs (BC), Link Within Text (TXT), Sitemap (SM), View Posting (VP), Office to Library (O2L), PDF Download (PDF). See Fig. 2 for Categories.

These data also show that the tree navigation was most popular among users. It is probably so attractive because all users are well acquainted with this form of navigation and it can be used easily because it is always visible on the screen (in contrast to the sitemap which has to be accessed specifically). The other methods of navigation were only used rarely. The average number of clicks for breadcrumbs (47.0) is due to one single user who used this form of navigation 482 times. The other users only adopted this form of navigation between 0 and 11 times. The same user also used the sitemap comparatively often. He clicked 479 times on the sitemap to access single pages. 


\section{Conclusion}

In principle, the participants found the Ecodesign e-learning course very interesting and engaging. There are probably several reasons for this. We tried to develop a very simple and usable system. Apparently, the users appreciated this. In addition, the contents of the course is seen as relevant for the work practice of the participants. Another factor is presumably also the example-oriented character of the system which allows for a more autonomous learning process than ordinary in vocational training.

There are, of course, single features of the system which were criticized but the system as a whole and especially the systemic and holistic approach was approved. Most of the participants worked through the material in the office section in a linear manner and, as a consequence, only used the navigational tree. A hypertextual organization of the material did not make very much sense for them. They see a fundamental difference between the office section of the Ecodesign e-learning system and the WWW in that they have to learn every page for Ecodesign but only search for specific pages in the WWW. The hypertextual organization of the system only makes sense during the solution of the examples for searching for specific domains within the dossiers.

Computer-mediated communication (CMC) played an important role in the Ecodesign course. The attitudes toward the various forms of CMC varied widely. Chat was criticized heavily. This might also be due to the fact that no participant had any previous experience with chat (low computer literacy). The discussion forum was seen as a preferable form of communication although it is an open question how this forum should be organized to ensure continuous participation of all learners. Because of the high workload of the learners a rigid schedule for electronic communication might be necessary also in a discussion forum.

The participants all found that the online tutor was extremely helpful and very important for their work. The fact that all participants finished the course successfully is probably due to the concept of active tutoring.

\section{Acknowledgements}

Special thanks to Stephan Sykacek who gave valuable input for unraveling the logfiles.

The project "eLearning Kurs zu umweltgerechter Produktgestaltung / ECODESIGN" is financed by the European Social Fund (esf) and the Austrian Ministry for Education, Science and Culture.

\section{References}

[CM03] Clark, R.C.; Mayer, R.E.: e-Learning and the Science of Instruction. San Francisco: Pfeiffer, 2003

[Da05] Dalsgaard, C.: Pedagogical quality in e-learning. Designing e-learning from a learning theoretical approach. In: $e$ learning and education, Issue 1, February 2005

[Ho01] Holmberg, B.: Distance Education in Essence. Oldenburg: Bibliotheks- und Informationssystem der Universität Oldenburg, 2001

[JHG03] Jarvis, P.; Holford, J.; Griffin, C.: The theory \& practice of learning. Second edition, London, Sterling: Kogan Page, 2003

[LA04] Lawless, N.; Allan, J.: Understanding and reducing stress in collaborative e-Learning. In: Electronic Journal of eLearning, Vol. 2, Issue 1, 2004

[Lo02] Lowyck, J.: Pedagogical Design. In (Adelsberger, H.H.; Collis, B.; Pawlowski, J.M., eds.): Handbook on Information Technologies for Education and Training. Berlin, Heidelberg, New York: Springer, 2002; S.199-217

[MN04] McPherson, M.; Nunes, M.B.: The Role of Tutors as an Integral Part of Online Learning Support. In: EURODL European Journal of Open, Distance and E-Learning. Issue 2004/I, 2004

[Ni00] Nielsen, J.: Erfolg des Einfachen, München: Markt+Technik Verlag, 2000

[Po04] Pohl, M.: Guidelines for E-Learning - Advantages and Disadvantages. In: Proceedings of the ED-MEDIA 2004, $4827-4830$ 
[PR04] Pohl, Margit; Rester, Markus: Ecodesign: Development and Testing of an E-learning System. In (Auer, M.; Auer, U., eds.): ICL: Interactive Computer Aided Learning. Proceedings of the International Conference. Kassel: kassel university press, 2004. - ISBN 3-89958-089-3

[PRS02] Preece, J.; Rogers, I.; Sharp, H.: Interaction Design, New York: John Wiley \& Sons, 2002

[RS02] Rudestam, K.E.; Schoenholtz-Read, J.: Overview - The coming of Age of Adult Education. In (K.E. Rudestam; J. Schoenholtz-Read, eds.): Handbook of Online Learning. Thousand Oaks, London, New Delhi: Sage Publications, 2002; 3-28

[RV03] Reichl, F.; Vierlinger, U.; Tutor-enhanced eLearning for University Based Continuing Education. In: Proceedings of the ED-MEDIA 2003, 1633-1640

[Sc97] Schulmeister, R.: Grundlagen hypermedialer Lernsysteme, München: R.Oldenburg Verlag, 1997

[Sc01] Schulmeister, R.; Virtuelle Universität - Virtuelles Lernen, München: R.Oldenburg Verlag, 2001

[WZ01] Wimmer, W.; Züst, R.: ECODESIGN PILOT: Produkt-Innovations-, Lern- und Optimierungstool für umweltgerechte Produktgestaltung mit deutsch/englischer CD-ROM. Zürich, CH: Verlag Industrielle Organisation, 2001 